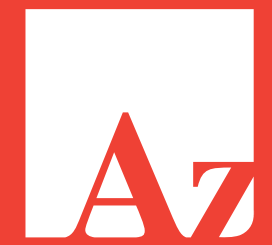

\title{
Alzheimer's Disease International
}

The global voice on dementia

\section{Policy Brief for Heads of Government}

\section{The Global Impact of Dementia 2013-2050}

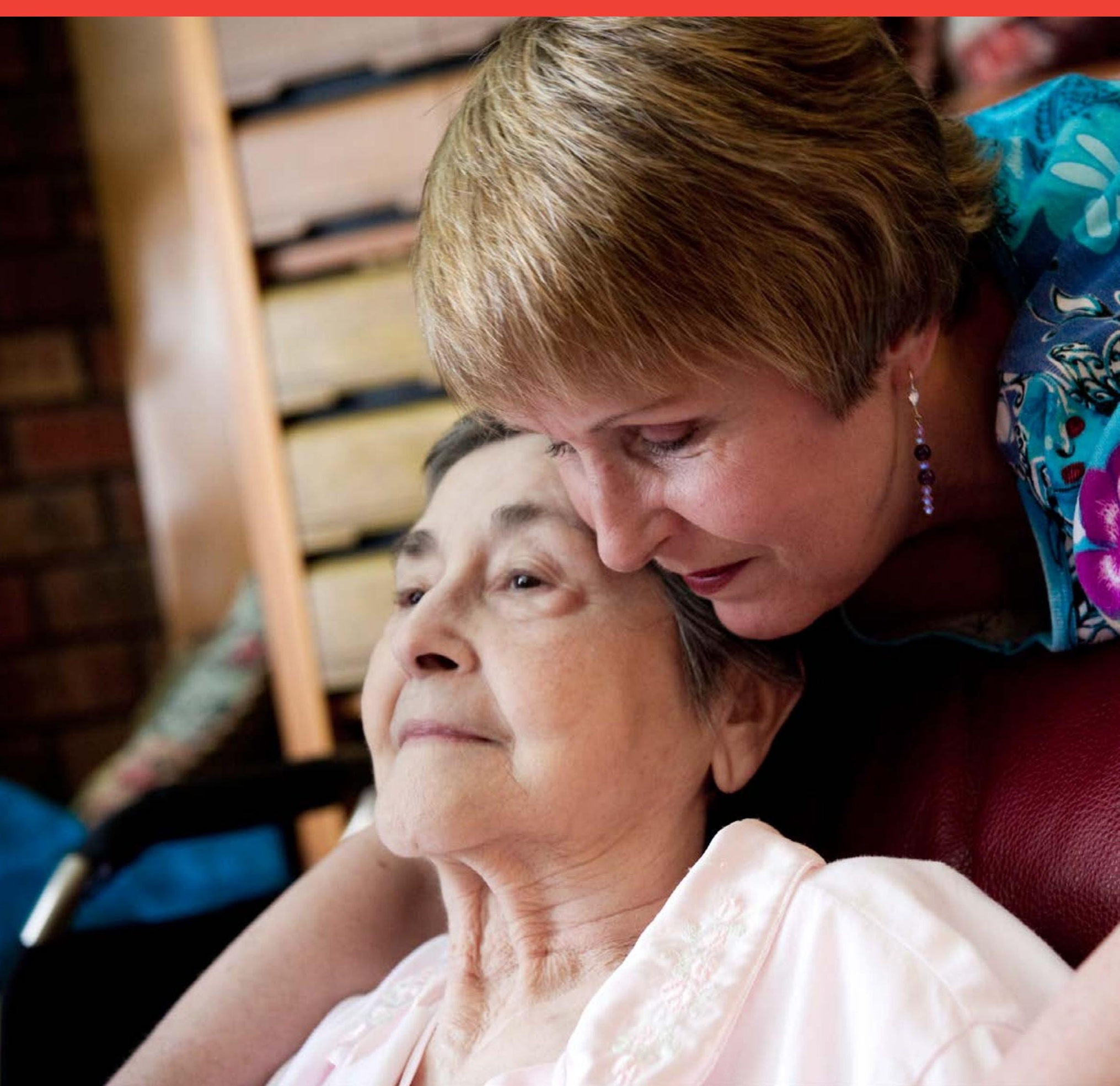




\section{The Global Impact of Dementia 2013-2050}

Although high income countries, including the G8, have borne the brunt of the dementia epidemic, this is a global phenomenon. Most people with dementia live in low and middle income countries, and most of the dramatic increases in numbers affected, through to 2050, will occur in those regions. In a spirit of international cooperation and solidarity we urge the G8 governments to sponsor intergovernmental action to make dementia a global priority. Crucially, this must include opening up access to diagnosis and current evidence-based treatment and care. All countries worldwide are failing in this basic objective. Action to address this problem should be balanced, as a priority, with research to improve treatment options and quality of care.

\section{Introduction}

Alzheimer's Disease International (ADI) published global prevalence data on dementia in the World Alzheimer Report $2009^{1}$ based on a systematic review of 154 studies conducted worldwide, and United Nations population projections through to the year 2050 . We estimated 36 million people with dementia in 2010, nearly doubling every 20 years to 66 million by 2030 and to 115 million by 2050 .

\section{Key findings included}

- $58 \%$ of those affected lived in low and middle income countries, underlining the high impact of the condition in those regions, where awareness is low, health and social care are poorly developed and social protection is limited.

- Population ageing is the main driver of projected increases.

- We assumed that age-specific prevalence would remain constant. This assumption is challenged by recent evidence suggesting a modest recent decline in dementia prevalence in some higher income countries $(\mathrm{HIC})$, but an increase in prevalence in China, likely linked to recent changes in population health, particularly exposure to cardiovascular risk factors.

- Since population ageing is occurring at an unprecedentedly fast rate in middle income countries, the bulk of the increase in numbers through to 2050 will occur in those regions. By $205071 \%$ of those with dementia would be living in what are currently lower and middle-income countries (LMIC).
Since 2009, the global evidence base has expanded, most particularly with a new systematic review of the prevalence of dementia in China ${ }^{3}$ comprising 75 studies, most published in Chinese language journals, and with seven studies from five subSaharan African countries, where previously only one study from Nigeria had been available.

The G8 Dementia Summit on 11 December 2013 provides a timely opportunity to reassess and update evidence on the scale and the distribution of the global dementia epidemic, in particular its impact on more developed (G8, G20, OECD and 'high income' countries) and less developed 'low and middle income' countries.

For the current update, we carried out a limited review, focusing on the new evidence emerging from China and the sub-Saharan African regions, and applied the new prevalence proportions to the latest (2012) UN population projections ${ }^{2}$. Details of the methodology are provided in Annex 1.

The work on this report has been a joint effort of the Global Observatory for Ageing and Dementia Care (Prof Martin Prince, Dr Maëlenn Guerchet and Dr Matthew Prina), and the ADI office. 


\section{Results}

The prevalences of dementia estimated from the recent more comprehensive review and metaanalysis of China studies ${ }^{3}$ and our own metaanalysis of studies from sub-Saharan Africa were substantially higher than those used in the 2009 World Alzheimer Report. Age-standardised to a standard West European population, prevalence for East Asia increased from $4.98 \%$ to $6.99 \%$ and in the sub-Saharan African regions from a range of $2.07 \%$ to $4.00 \%$, to $4.76 \%$ (Figure 1 ).
The net effect, as more data becomes available, is to further reduce the variation in prevalence between world regions.

The number of people living with dementia worldwide in 2013 is estimated at 44.35 million, reaching 75.62 million in 2030 and 135.46 million in 2050 (Figure 2). The updated estimates are higher than our original estimates reported in the 2009 World Alzheimer Report, by $15 \%$ in 2030, and by $17 \%$ in 2050 .

Figure 1 Original (2009 World Alzheimer Report) and updated age-specific prevalence of dementia (\%) by region, showing impact of new data from Asia East (China) and Sub-Saharan Africa

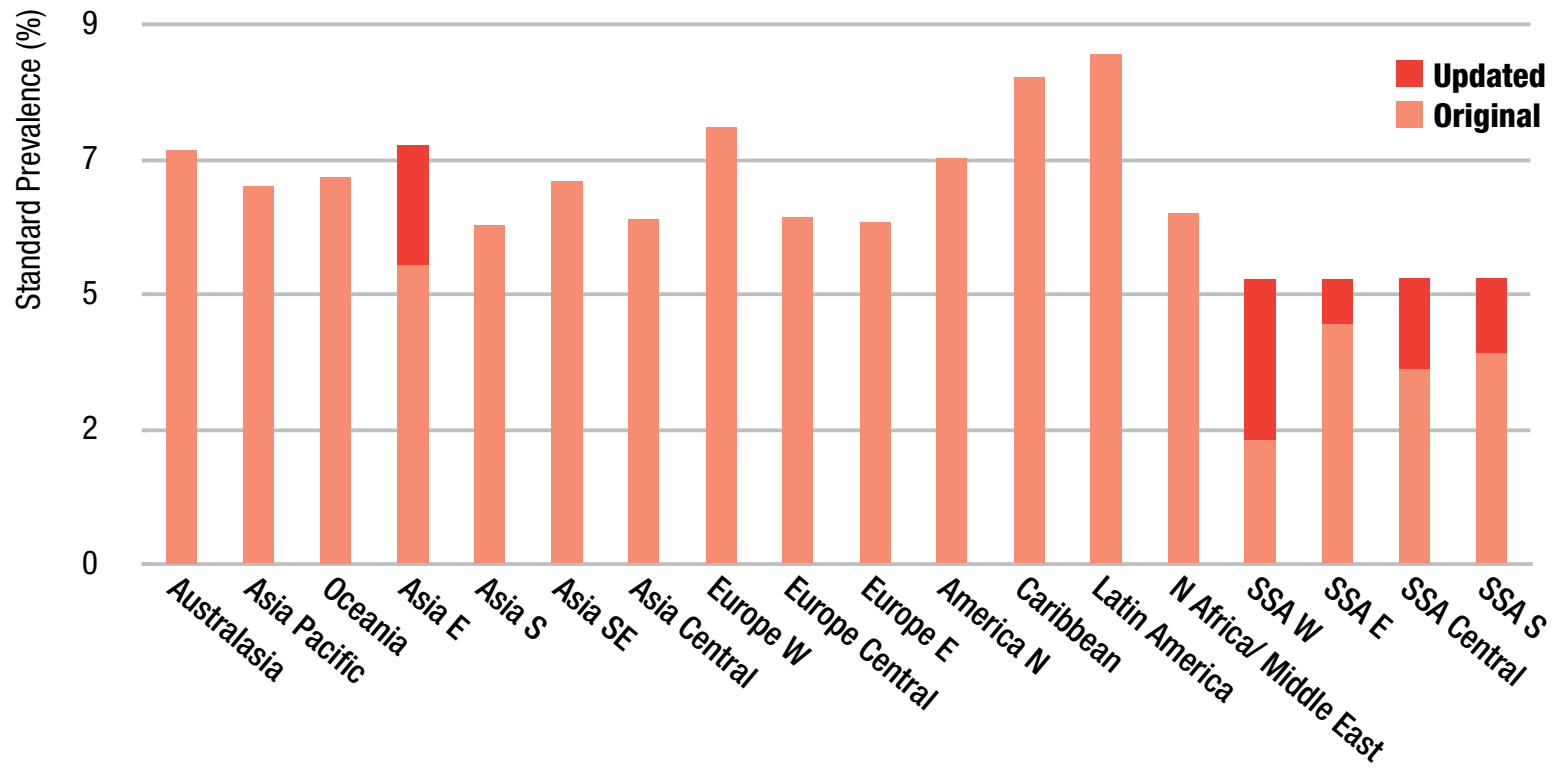

Figure 2 Increase in numbers of people with dementia worldwide (2010-2050), comparing original and updated estimates
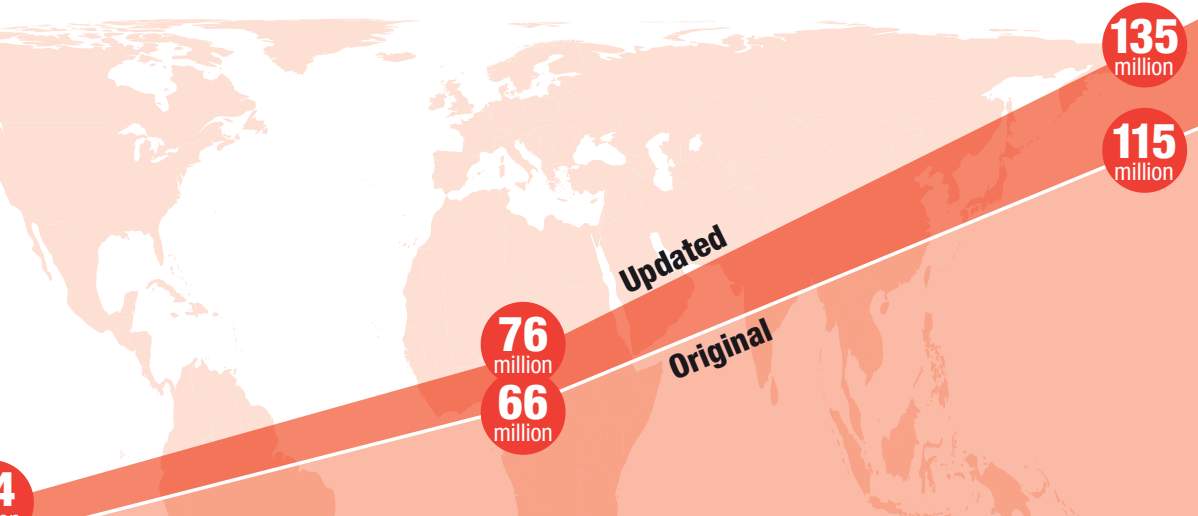
The largest increases in projected numbers of people with dementia are those for the Asia East and Sub-Saharan African regions, accounted for by the higher age-specific prevalence of dementia estimated in our new reviews of survey data from those regions (Annex 2). Hence, in 2050 we are now estimating 33.61 million people with dementia in Asia East (an increase of $49 \%$ from the previous estimate of 22.54 million) and 5.05 million older people with dementia in SSA (an increase of $136 \%$ from the previous estimate of 2.14 million). However, the new estimates of numbers of people with dementia are higher for all GBD regions than those estimated in 2009.
This is explained by the underestimation of current numbers of older people in the previous UN population estimates (affecting the 2013 figures), and revision upwards of probability of survival into older age (affecting the 2030 and 2050 projections).

We now estimate that while $32 \%$ of people with dementia live in G8 countries and 38\% in high income countries, $62 \%$ live in low and middle income countries (Table 1). By 2050, the proportion living in G8 countries will have shrunk to $21 \%$, while the proportion living in what are currently low and middle income countries will have increased to $71 \%$.

Table 1 Updated estimates of the number of people with dementia living in G8, G20, OECD, LMIC and HIC countries, and as a percentage of world total

\begin{tabular}{l|c|c|c|c|c}
\multirow{2}{*}{ Region } & \multicolumn{3}{|c|}{$\begin{array}{c}\text { People with dementia millions } \\
\text { (\% of world total) }\end{array}$} & $\begin{array}{c}\text { Proportionate increase } \\
(\%)\end{array}$ \\
\cline { 2 - 6 } & 2013 & 2030 & 2050 & $2013-2030$ & $2013-2050$ \\
\hline G8 & $14.02(32 \%)$ & $20.38(27 \%)$ & $28.91(21 \%)$ & 45 & 106 \\
\hline G20 & $33.93(76 \%)$ & $56.40(75 \%)$ & $96.61(71 \%)$ & 66 & 185 \\
\hline OECD & $18.08(41 \%)$ & $27.98(37 \%)$ & $43.65(32 \%)$ & 55 & 142 \\
\hline High income & $17.00(38 \%)$ & $25.86(34 \%)$ & $39.19(29 \%)$ & 52 & 131 \\
\hline Low and middle income & $27.84(62 \%)$ & $49.76(66 \%)$ & $96.27(71 \%)$ & 79 & 246 \\
\hline World & 44.35 & 75.62 & 135.46 & 71 & 205 \\
\hline
\end{tabular}

Figure 3 Number of people with dementia in low and middle income countries compared to high income countries

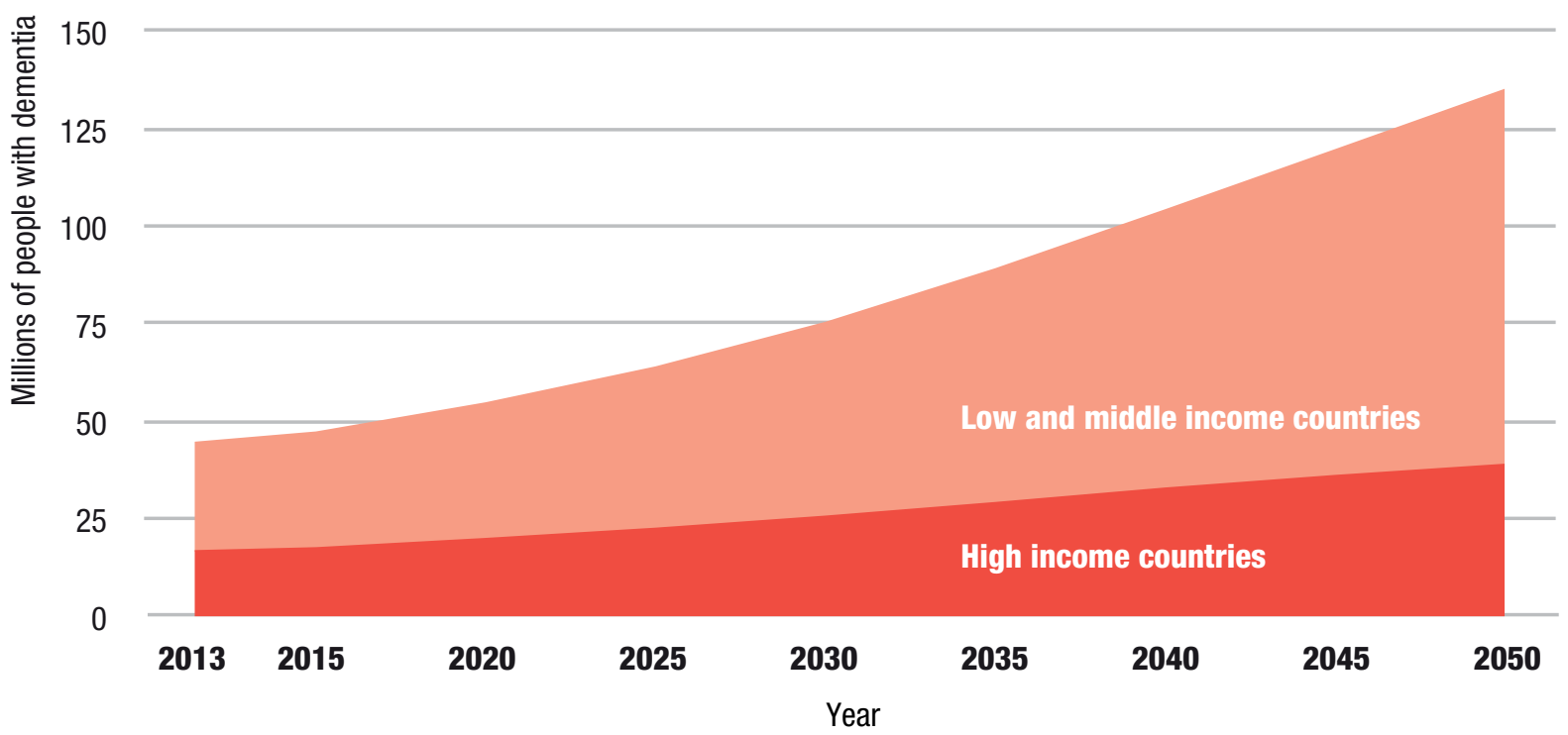




\section{Conclusions and implications}

1 Dementia, including Alzheimer's disease, is one of the biggest global public health challenges facing our generation. Newly available data suggests that the current burden and future impact of the dementia epidemic has been underestimated, particularly for the Asia East and Sub-Saharan African regions.

2 This is a global epidemic - although cases are disproportionately concentrated in the world's richest and most demographically aged countries, already the clear majority $(62 \%)$ of people with dementia live in low and middle income countries where access to social protection, services, support and care are very limited.

3 In the next few decades, the global burden of dementia will shift inexorably to poorer countries, particularly rapidly developing middle income countries that are members of the G20, but not the G8.

4 The future scale of the dementia epidemic may be blunted through improvements in population health, but our best estimates suggest that only up to $10 \%$ of incidence may thus be avoided ${ }^{13}$. Public health and disease control measures targeting smoking, underactivity, obesity, hypertension and diabetes should be prioritised. Education and other factors that enhance brain and cognitive development will also improve the brain health of those entering old age, and reduce the incidence of dementia in late life.

5 Standard \& Poor's has described global population ageing as the biggest threat to the sustainability of sovereign debt. Among the chronic diseases, dementia makes by far the largest single contribution to disability and needs for care among older people. The current (2010) global societal economic cost of dementia is US\$ 604 billion, or $1 \%$ of global $\mathrm{GDP}^{14}$. Costs will escalate proportionately with numbers affected, and with increased demand for formal care services, particularly in low and middle income countries ${ }^{13}$.

6 Research must be a global priority if we are to improve the quality and coverage of care, find treatments that alter the course of the disease, and identify more options for prevention.

7 Investment in the search for a cure must be balanced with initiatives to improve access to currently available evidence-based packages of care - these include timely diagnosis; case management across the course of the illness; support, education and training for carers; optimising physical health; acetylcholinesterase inhibitors; cognitive stimulation; and non-pharmacological interventions for behavioural disturbance. Currently less than half of those in high income countries and fewer than $10 \%$ of those in LMIC have received a dementia diagnosis.

8 There are lessons to be drawn from the HIV epidemic. First, new and dramatically effective treatments can only be scaled up when diagnostic and care systems are well established. Second, affordable access to new diagnostic technologies and drug therapies will need rapidly to be extended to low and middle income country markets, where most of those who might benefit live. Third, those countries that where involved in 'global trials' should also benefit from treatments being made available at subsidised cost with adequate standards of care in place.

$9 \mathrm{ADI}$ and the World Health Organization have, in their joint report Dementia: a public health priority ${ }^{13}$, called upon all Governments to make dementia a public and health priority. As part of this process, all governments should initiate national debates regarding the future provision and financing of long-term care (see World Alzheimer Report 2013: Journey of Caring ${ }^{15}$ ). However, most are woefully unprepared for the dementia epidemic with only 13 countries having funded and sought to implement a national dementia plan. Without a plan, the risk is that health and social care systems will not cope with the increase in numbers and operate in crisis mode, escalating costs even further.

10 At the eve of the G8 Dementia Summit in London, UK, it is not just the G8 countries, but all nations that must commit to a sustained increase in dementia research and a comprehensive plan for collaborative action involving all relevant government sectors, industry and civil society. International cooperation will be essential. There is a need for a collaborative, global action plan for governments, industry and non-profit organisations like Alzheimer associations. Priorities include; breaking down barriers to effective research; promoting rapid translation and ensuring equitable access to promising technologies and treatments; technical support for policymaking, health and social care service and system development. 


\section{References}

1 Alzheimer's Disease International: World Alzheimer Report 2009. 2009.

2 United Nations Department of Economic and Social Affairs Population Division: World Population Prospects: The 2012 Revision, DVD Edition. 2013.

3 Chan KY, Wang W, Wu JJ, Liu L, Theodoratou E, Car J, Middleton L, Russ TC, Deary IJ, Campbell H et al: Epidemiology of Alzheimer's disease and other forms of dementia in China, 1990-2010: a systematic review and analysis. The Lancet 2013, 381(9882):2016-2023.

4 Wu YT, Lee HY, Norton S, Chen C, Chen H, He C, Fleming J, Matthews FE, Brayne C: Prevalence studies of dementia in mainland china, Hong Kong and taiwan: a systematic review and meta-analysis. PLoS ONE 2013, 8(6):e66252.

5 Jia J, Wang F, Wei C, Zhou A, Jia X, Li F, Tang M, Chu L, Zhou Y, Zhou C et al: The prevalence of dementia in urban and rural areas of China. Alzheimers Dement 2013.

6 Hendrie HC, Osuntokun BO, Hall KS, Ogunniyi AO, Hui SL, Unverzagt FW, Gureje O, Rodenberg CA, Baiyewu O, Musick BS: Prevalence of Alzheimer's disease and dementia in two communities: Nigerian Africans and African Americans. Am J Psychiatry 1995, 152(10):1485-1492.

7 Guerchet M, Houinato D, Paraiso MN, von Ahsen N, Nubukpo P, Otto M, Clement JP, Preux PM, Dartigues JF: Cognitive impairment and dementia in elderly people living in rural Benin, west Africa. Dement Geriatr Cogn Disord 2009, 27(1):34-41.

\section{Annex 1: Methods}

\section{The prevalence of dementia in China and Sub-Saharan Africa}

The estimates for China were revised based on the recent meta-analysis published by Chan et al. ${ }^{3}$. This metaanalysis included reports for dementia or Alzheimer's Disease in mainland China, published in Chinese and English between 1990 and 2010. The rates applied to the population estimates were the age-specific prevalence of dementia in 2010. A new systematic review of dementia in China has also been recently published ${ }^{4}$, together with a new large multi-centre population-based prevalence study of dementia in China ${ }^{5}$. These studies were not taken into account in our estimates, but will be included in any future updates.

For Sub-Saharan Africa, we conducted a systematic review of the literature on the prevalence of dementia with Pubmed / Medline up to October 2013 using a similar methodology and inclusion criteria that we used for the 2009 World Alzheimer Report ${ }^{1}$ (see online appendix). We sought and included population-based studies of the prevalence of dementia among people aged 60 years and over for which the fieldwork started on or after 1st January 1980. Prevalence rates were extracted for seven studies covering five different countries ${ }^{6-12}$. A random effect exponential (Poisson) model was used to assess the effects of age on the prevalence of dementia. We then applied the relevant mean ages to the coefficients estimated from the model, to estimate prevalence in five year age-bands from 65-69 years to 85 years and over, for both sexes combined.
8 Guerchet M, M'Belesso P, Mouanga AM, Bandzouzi B, Tabo A, Houinato DS, Paraiso MN, Cowppli-Bony P, Nubukpo P, Aboyans $V$ et al: Prevalence of dementia in elderly living in two cities of Central Africa: the EDAC survey. Dement Geriatr Cogn Disord 2010, 30(3):261-268.

9 Paraiso MN, Guerchet M, Saizonou J, Cowppli-Bony P, Mouanga AM, Nubukpo P, Preux PM, Houinato DS: Prevalence of dementia among elderly people living in Cotonou, an urban area of Benin (West Africa). Neuroepidemiology 2011, 36(4):245-251.

10 Yusuf AJ, Baiyewu O, Sheikh TL, Shehu AU: Prevalence of dementia and dementia subtypes among communitydwelling elderly people in northern Nigeria. Int Psychogeriatr 2011, 23(3):379-386.

11 Longdon AR, Paddick SM, Kisoli A, Dotchin C, Gray WK, Dewhurst F, Chaote P, Teodorczuk A, Dewhurst M, Jusabani AM et al: The prevalence of dementia in rural Tanzania: a cross-sectional community-based study. Int J Geriatr Psychiatry 2013, 28(7):728-737.

12 Guerchet M, Banzouzi-Ndamba B, Mbelesso P, Pilleron S, Clement J-P, Dartigues J-F, Preux P-M.: Prevalence of dementia in two countries of Central Africa: comparison or rural and urban areas in the EPIDEMCA study. Neuroepidemiology 2013, 41:223-316.

13 World Health Organization and Alzheimer's Disease International, Dementia: a public health priority, Geneva April 2012, http://www.alz.co.uk/WHO-dementia-report

14 Wimo A, Prince M. World Alzheimer Report 2010; The Global Economic Impact of Dementia. 2010. London, Alzheimer's Disease International

15 World Alzheimer Report 2013, Journey of Caring, An analysis of long-term care for dementia, http://www.alz. co.uk/research/world-report-2013

\section{Estimation of the number of people with dementia}

The new rates were applied to the new UN population estimates for each 5-years age band (60-64, to 100 and over $)^{2}$. When rates were not available for one age-band (i.e. over 90 in SSA and over 100 in China), the rate of the nearest age-band was applied. As gender-specific estimates were available neither for China nor SSA, we applied the age-specific estimates to the whole population and to each gender separately. In the East Asia region - composed of China, Hong Kong SAR, Macao SAR, Chinese Taipei and DPR Korea - the new rates were applied to mainland China, Hong Kong SAR and Macao SAR, whereas the East Asia rates from the 2009 Word Alzheimer Report were maintained for the DPR Korea and Chinese Taipei.

For Sub-Saharan Africa, the new rates were applied to the countries belonging to the following Global Burden Disease (GBD) regions: SSA West, SSA Central, SSA East and SSA Southern. Based on the GBD regions, Algeria belongs to the North Africa / Middle East, so we therefore applied the EMRO B rates that are used for some of its neighbours.

For all the other regions, we applied the rates found in the 2009 World Alzheimer Report to the new population estimates from the United Nations ${ }^{2}$. 
Annex 2

Table 1 Numbers of people with dementia according to GBD regions (in millions, by year)

\begin{tabular}{|c|c|c|c|c|c|c|c|c|}
\hline \multirow[b]{2}{*}{ GBD Region } & \multicolumn{3}{|c|}{ Original estimates (2009) } & \multicolumn{3}{|c|}{ Updated estimates } & \multicolumn{2}{|c|}{$\begin{array}{l}\text { Proportionate increases } \\
(\%) \text { for new estimates }\end{array}$} \\
\hline & 2010 & 2030 & 2050 & 2013 & 2030 & 2050 & $2013-2030$ & $2013-2050$ \\
\hline Asia/Pacific & 15.94 & 33.04 & 60.92 & 21.87 & 39.79 & 71.84 & 82 & 228 \\
\hline Australasia & 0.31 & 0.53 & 0.79 & 0.37 & 0.62 & 1.02 & 68 & 176 \\
\hline Asia Pacific High Income & 2.83 & 5.36 & 7.03 & 3.26 & 5.50 & 7.58 & 69 & 133 \\
\hline Oceania & 0.02 & 0.04 & 0.10 & 0.02 & 0.04 & 0.09 & 100 & 350 \\
\hline Asia Central & 0.33 & 0.56 & 1.19 & 0.29 & 0.44 & 0.88 & 52 & 203 \\
\hline Asia East & 5.49 & 11.93 & 22.54 & 10.46 & 18.83 & 33.61 & 80 & 221 \\
\hline Asia South & 4.48 & 9.31 & 18.12 & 4.74 & 8.50 & 16.61 & 79 & 250 \\
\hline Asia Southeast & 2.48 & 5.30 & 11.13 & 2.74 & 5.87 & 12.05 & 114 & 340 \\
\hline Europe & 9.95 & 13.95 & 18.65 & 10.93 & 14.8 & 20.75 & 35 & 90 \\
\hline Europe Central & 1.10 & 1.57 & 2.10 & 1.23 & 1.69 & 2.29 & 37 & 86 \\
\hline Europe Eastern & 1.87 & 2.36 & 3.10 & 1.86 & 2.03 & 2.44 & 9 & 31 \\
\hline Europe Western & 6.98 & 10.03 & 13.44 & 7.84 & 11.08 & 16.02 & 41 & 104 \\
\hline The Americas & 7.82 & 14.78 & 27.08 & 8.77 & 15.8 & 30.51 & 80 & 248 \\
\hline North America High Income & 4.38 & 7.13 & 11.01 & 4.58 & 7.28 & 11.74 & 59 & 156 \\
\hline Caribbean & 0.33 & 0.62 & 1.04 & 0.38 & 0.63 & 1.14 & 66 & 200 \\
\hline Latin America Andean & 0.25 & 0.59 & 1.29 & 0.31 & 0.64 & 1.46 & 106 & 371 \\
\hline Latin America Central & 1.19 & 2.79 & 6.37 & 1.38 & 2.95 & 7.07 & 114 & 412 \\
\hline Latin America Southern & 0.61 & 1.08 & 1.83 & 0.71 & 1.17 & 2.13 & 65 & 200 \\
\hline Latin America Tropical & 1.05 & 2.58 & 5.54 & 1.42 & 3.13 & 6.97 & 120 & 391 \\
\hline Africa & 1.86 & 3.92 & 8.74 & 2.78 & 5.24 & 12.35 & 88 & 344 \\
\hline North Africa / Middle East & 1.15 & 2.59 & 6.19 & 1.47 & 2.91 & 7.29 & 98 & 396 \\
\hline Sub-Saharan Africa Central & 0.07 & 0.12 & 0.24 & 0.13 & 0.23 & 0.48 & 77 & 269 \\
\hline Sub-Saharan Africa East & 0.36 & 0.69 & 1.38 & 0.55 & 1.06 & 2.45 & 93 & 345 \\
\hline Sub-Saharan Africa Southern & 0.10 & 0.17 & 0.20 & 0.19 & 0.29 & 0.49 & 53 & 158 \\
\hline Sub-Saharan Africa West & 0.18 & 0.35 & 0.72 & 0.44 & 0.76 & 1.63 & 73 & 270 \\
\hline World & 35.56 & 65.69 & 115.38 & 44.35 & 75.62 & 135.46 & 71 & 205 \\
\hline
\end{tabular}

\section{Acknowledgements}

\section{Authors}

Prof Martin Prince *

Dr Maëlenn Guerchet *

Dr Matthew Prina *

Alzheimer's Disease International

* Global Observatory for Ageing and Dementia Care,

Health Service and Population Research Department, King's College London

\section{Thanks to}

Pr Richard Walker, Dr Catherine Dotchin and Dr William Keith Gray from the Northumbria Healthcare NHS Foundation Trust, the Institute for Ageing and Health, and the Institute of Health and Society, in Newcastle University (UK) for providing us prevalence rates from their study in Tanzania.

Pr Pierre-Marie Preux, from the UMR Inserm 1094 Tropical Neuroepidemiology in Limoges (France), and the EPIDEMCA group, for allowing us to include their last results in Central Africa before their publication.

Cover image $\odot$ Barbara Kinney, used with permission of Alzheimer's Association (US). 


\section{About Alzheimer's Disease International}

Alzheimer's Disease International (ADI) is the international federation of Alzheimer associations throughout the world. Each of our 79 members is a non-profit Alzheimer association supporting people with dementia and their families.

ADI was founded in 1984 and registered as a non-profit organization in the USA. Based in London, ADI is in official relations with the WHO since 1996 and has consultative status with the UN since 2012.

ADI's vision is an improved quality of life for people with dementia and their families throughout the world. ADI aims to make dementia a global health priority, to build and strengthen Alzheimer associations, and to raise awareness about dementia worldwide. Stronger Alzheimer associations are better able to meet the needs of people with dementia and their carers, and to be the global voice on dementia.

\section{Global Observatory for Ageing and Dementia Care}

The Global Observatory for Ageing and Dementia Care, hosted at the Health Service and Population Research Department, King's College London, was founded in 2013. Supported by Alzheimer's Disease International and King's College London, the Observatory aims to synthesise global evidence for policymakers and the public through high impact evidence-based reports for Alzheimer's Disease International (World Alzheimer Reports 2009, 2010, 2011 and 2013), the World Health Organization (Dementia; a public health priority) and other relevant intergovernmental organisations. A particular focus is to identify and promote effective innovations in health and social care policy and practice.

Alzheimer's Disease International: The International Federation of Alzheimer's Disease and Related Disorders Societies, Inc. is incorporated in Illinois, USA, and is a 501(c)(3) not-for-profit organization
Alzheimer's Disease International 64 Great Suffolk Street London SE1 OBL UK

Tel: +442079810880

Fax: +44 2079282357

www.alz.co.uk

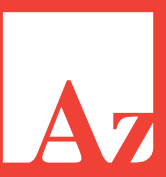

Azheimer's Disease International

The global voice on dementia 